\title{
Protein and amino acid bioavailability estimates for canine foods
}

\author{
W. H. Hendriks, $* 1+$ E. J. Bakker, ${ }^{\dagger}$ and G. Bosch* \\ *Animal Nutrition Group, Wageningen University, PO Box 338, 6700 AH, Wageningen, The Netherlands; \\ $\dagger$ Faculty of Veterinary Medicine, Utrecht University, PO Box 80.151, 3508 TD, Utrecht, The Netherlands; \\ and $\$$ Mathematical and Statistical Methods, Wageningen University, PO Box $6700 \mathrm{AA}$, Wageningen, The Netherlands
}

\begin{abstract}
Estimates of nutrient bioavailability are required for establishing dietary nutrient requirements and to evaluate the nutritional value of food ingredients or foods that are exposed to processing or extended storage. This study aimed to generate estimates for the bioavailability of dietary $\mathrm{CP}$ and AA for adult dogs using existing literature data and to evaluate the accuracy of estimates currently used in 3 authoritative publications. A regression equation was derived relating apparent fecal $\mathrm{N}$ outflow to standardized ileal $\mathrm{N}$ outflow from a data set containing information on 158 individual diets and their $\mathrm{N}$ digestibility when fed to adult dogs. Standardized ileal digestibility (sID) of $\mathrm{N}\left(\mathrm{sID}_{\mathrm{N}}\right)$ was shown to be nearly perfectly correlated to the SID of the sum of $\mathrm{N}$ of AA in 24 diets for which AA digestibility data were available. Regression equations between SID of indi-
\end{abstract}

vidual $\mathrm{AA}$ and $\mathrm{sID}_{\mathrm{N}}$ were calculated. Bioavailability estimates were subsequently derived from simulated SID values of $\mathrm{N}$ and essential and nonessential $\mathrm{AA}$ for 10 diets varying in $\mathrm{CP}$ content (18 to $42 \%$ ) and apparent fecal $\mathrm{N}$ digestibility (70 and $80 \%$ ) for an adult dog of $20 \mathrm{~kg} \mathrm{BW}$. Calculated bioavailability estimates of the NRC for maintenance dog foods do not lead to realistic nutrient allowance estimates for $\mathrm{CP}$ and AA. Estimates used by the Association of American Feed Control Officials and the European Pet Food Industry Federation were closer to calculated values, although the majority were too low, with the exception of CP, Arg, and Lys. Bioavailability estimates for Lys, Met, and $\mathrm{Cys}$ as calculated here require further veracity as the chemical form in which these AA are present in commercial pet foods may significantly reduce their bioavailability.

Key words: bioavailability estimates, digestibility, dogs, maintenance, simulation

(C) 2015 American Society of Animal Science. All rights reserved.

J. Anim. Sci. 2015.93:4788-4795 doi:10.2527/jas2015-9231

\section{INTRODUCTION}

Bioavailability of dietary AA is an important aspect for the determination of the nutritional quality of animal diets including those for dogs and cats. Amino acid bioavailability can be defined as the proportion of an ingested AA absorbed from the gastrointestinal tract in a form that can potentially be utilized by metabolism (Batterham, 1992). Although not directly measurable, dietary AA bioavailability includes not only digestibility of dietary AA but also the chemical form absorbed (Stein et al., 2007). Bioavailability of dietary AA should be estimated from digestibility measurements obtained at the ileal level corrected for endogenous AA losses,

\footnotetext{
${ }^{1}$ Corresponding author: wouter.hendriks@wur.nl

Received April 23, 2015.

Accepted August 2, 2015.
}

as the large intestine makes an insignificant contribution to overall AA supply but the microflora in the large intestine do metabolize dietary and endogenous AA (Hendriks et al., 2012). However, as ileal digestibility measurement in dogs is difficult in terms of ethics and economics, its routine measurement is not feasible.

Based on a typical estimated bioavailability of 0.80 , a constant value of $1.25(1 / 0.8)$ is used by the NRC (2006) to convert minimal requirements based on bioavailable dietary nutrient levels to "allowances" or "minimal inclusion estimates" based on total dietary nutrient levels. This estimate of bioavailability is suggested to reflect observations that commercial pet foods rarely have apparent fecal CP digestibility values below 0.80 (Q. R. Rogers formerly employed at UC Davis, retired; personal communication). Two other authoritative associations in companion animal nutrition (AAFCO, 2011; FEDIAF, 2012) use different 
estimates (1.0-2.25) to derive minimal $\mathrm{CP}$ and AA inclusion estimates from minimum nutrient requirement estimates of the NRC $(1995,2006)$. As already identified by Morris and Rogers (1994), bioavailability estimates for most nutrients (including $\mathrm{CP}$ and AA) as used by the NRC (2006), the Association of American Feed Control Officials (2011), and the European Pet Food Industry Federation (2012) are inadequately referenced, not citing scientific studies, and still lack scientific veracity.

This study aimed to generate estimates for the bioavailability of dietary CP and AA for adult dogs using existing literature data and to evaluate the accuracy of estimates currently used in authoritative publications.

\section{MATERIALS AND METHODS}

\section{Approach}

Existing literature data were used to generate estimates for the bioavailability of $\mathrm{CP}$ and AA in diets for adult dogs. For this, one regression equation was developed to predict standardized ileal $\mathrm{N}$ digestibility based on fecal CP digestibility and one was developed to predict standardized ileal AA digestibility based on standardized ileal $\mathrm{N}$ digestibility. To gain insight into the precision of the bioavailability estimates for 10 different hypothetical diets, confidence limits were calculated using a simulation procedure. The lower limits of the bioavailability estimates for these diets were compared with the safety estimates currently used by the NRC (2006), the Association of American Feed Control Officials (2011), and the European Pet Food Industry Federation (2012).

\section{Data used to Derive Equations}

A previously reported data set (Hendriks et al., 2012) was supplemented with data from 5 studies (Zentek, 1995; Johnson et al., 1998; Gajda et al., 2005; Hendriks et al., 2013; Tjernsbekk et al., 2014) to contain data on 158 canine diets used in fundamental nutritional research, formulated to evaluate specific ingredients or investigate specific technological treatments. The data set contained information on BW, food intake, dietary $\mathrm{N}$ content, and apparent fecal and apparent ileal digestibility of N. From 24 diets reported in 6 studies (Bednar et al., 2000; Clapper et al., 2001; Hendriks and Sritharan, 2002; Gajda et al., 2005; Hendriks et al., 2013; Tjernsbekk et al., 2014), apparent ileal digestibility values of individual AA were also collected. Studies where diets were used composed of only 1 protein source (e.g., soybean meal, meat meal) were excluded as these were considered to be not representative for commercial diet compositions.

\section{Regression Equations to Predict $C P$ and $A A$ Bioavailability}

Nitrogen intake $\left(\mathbf{I N}_{\mathbf{N}}\right)$, apparent ileal outflow of $\mathrm{N}$ $\left(\mathbf{a I O}_{\mathbf{N}}\right)$, standardized ileal outflow of $\mathrm{N}\left(\mathbf{S I O} \mathbf{N}_{\mathbf{N}}\right)$, and apparent fecal outflow of $\mathrm{N}\left(\mathbf{a F O}_{\mathbf{N}}\right)$ were calculated and expressed on a grams per (kilogram $\mathrm{BW}^{0.75}$ per day) basis. The $\mathrm{aIO}_{\mathrm{N}}$ was calculated as

$$
\mathrm{aIO}_{\mathrm{N}}=\mathrm{IN}_{\mathrm{N}} \times\left(100-\mathrm{aID}_{\mathrm{N}}\right) / 100,
$$

in which $\mathrm{IN}_{\mathrm{N}}$ is the reported average intake of $\mathrm{N}$ in grams per (kilogram BW ${ }^{0.75}$ per day) and $\mathbf{a I D}_{\mathbf{N}}$ is the reported apparent ileal digestibility of $\mathrm{N}$ value for the diet in percent. The ileal outflows were corrected to standardized values using endogenous $\mathrm{N}$ excretions $[\mathrm{g} /(\mathrm{kg}$ $\left.\mathrm{BW}^{0.75} \mathrm{~d}\right)$ ] of dogs fed a protein-free diet as reported by Hendriks et al. (2002). Endogenous losses (expressed per unit DMI) were converted to kilograms $\mathrm{BW}^{0.75}$ per day using the actual feed intake and BW data of dogs for each diet. The relationship between $\mathrm{sIO}_{\mathrm{N}}$ and $\mathrm{aFO}_{\mathrm{N}}$ was estimated using the linear regression model

$$
\mathrm{sIO}_{\mathrm{N}}=\mathrm{A}_{\mathrm{N}}+\mathrm{B}_{\mathrm{N}} \times \mathrm{aFO}_{\mathrm{N}}+\varepsilon_{1},
$$

in which $\mathbf{A}_{\mathbf{N}}$ is the intercept in grams per (kilogram $\mathrm{BW}^{0.75}$ per day), $\mathbf{B}_{\mathbf{N}}$ is the slope of the regression, and $\varepsilon_{1}$ is the error term.

For each of the 158 diets, the standardized ileal digestibility (SID) of N ( IID $\left._{\mathbf{N}} ; \%\right)$ was calculated as

$$
\operatorname{sID}_{\mathrm{N}}=100 \times\left(\mathrm{IN}_{\mathrm{N}}-\mathrm{sIO}_{\mathrm{N}}\right) / \mathrm{IN}_{\mathrm{N}}
$$

in which $\mathrm{IN}_{\mathrm{N}}$ is the measured intake of $\mathrm{N}$ in grams per (kilogram $\mathrm{BW}^{0.75}$ per day) and $\mathrm{sIO}_{\mathrm{N}}$ is the calculated standardized ileal outflow of $\mathrm{N}$ in grams per (kilogram $\mathrm{BW}^{0.75}$ per day).

For each AA, the standardized ileal outflow and sID of AA ( SID $\left._{\mathbf{A A}}\right)$ values were calculated for the 24 diets using the same approach as for $\mathrm{sID}_{\mathrm{N}}$ and $\mathrm{sIO}_{\mathrm{N}}$. Ileal endogenous Cys excretion of dogs fed a proteinfree diet was assumed to be $239.4 \mu \mathrm{g} / \mathrm{g}$ DMI (Hendriks et al., 2013). The relationship between the $\operatorname{sID}_{\mathrm{N}}$ and the sID of the sum of $\mathrm{N}$ of AA ( (ID $\left._{\Sigma \text { AAN }}\right)$ was determined by linear regression analysis where $\operatorname{sID}_{\Sigma \mathrm{AAN}}$ was calculated using the dietary intake, apparent ileal digestibility, endogenous losses, molecular weight, and molar percentage of $\mathrm{N}$ of individual AA. Aspartic acid and Glu were assumed to contain $1.5 \mathrm{~mol} \mathrm{~N} / \mathrm{mol} \mathrm{AA}$, as it is unknown which fraction of these AA were present as Asn and Gln in the diets. For each of the AA and N of $\mathrm{AA}$, the (mean) sID of the AA or $\mathrm{N}$ of $\mathrm{AA}\left(\operatorname{sID}_{\mathrm{AA}} ; \%\right)$ was assumed to be linearly related to $\operatorname{siD}_{N}(\%)$ :

$$
\operatorname{sID}_{\mathrm{AA}}=\mathrm{A}_{\mathrm{AA}}+\mathrm{B}_{\mathrm{AA}} \times \operatorname{sID}_{\mathrm{N}}+\varepsilon_{2},
$$


in which $\mathbf{A}_{\mathbf{A A}}$ is the intercept in percent, $\mathbf{B}_{\mathbf{A A}}$ is the slope of the regression line, and $\varepsilon_{2}$ is the error term.

\section{Crude Protein and AA Bioavailability Estimates of Hypothetical Diets}

The above derived relationships were used to predict the $\mathrm{sID}_{\mathrm{N}}$ and $\mathrm{sID}_{\mathrm{AA}}$ of 10 hypothetical diets for adult dogs with a preset CP content $(180,240,300$, 360 or $420 \mathrm{~g} / \mathrm{kg}$ ) and an apparent fecal digestibility of $\mathrm{N}\left(\mathbf{a F D}_{\mathbf{N}} ; 80\right.$ or $\left.70 \%\right)$. In these calculations, all diets were assumed to contain 16.75 MJ ME/kg DM and consumed by an adult dog with a BW of $20 \mathrm{~kg}$ to meet energy requirements for maintenance $(544 \mathrm{~kJ} \mathrm{ME} / \mathrm{kg}$ $\mathrm{BW}^{0.75} \cdot \mathrm{d}$; NRC, 2006). Based on the dietary CP content, the daily energy intake, and the $\mathrm{aFD}_{\mathrm{N}}$, values for $\mathrm{IN}_{\mathrm{N}}$ and $\mathrm{aFO}_{\mathrm{N}}$ were calculated. With relationship [2], the $\mathrm{sIO}_{\mathrm{N}}$ value was predicted, and using Eq. [3] and [4], the $\mathrm{sID}_{\mathrm{AA}}$ values were predicted for $11 \mathrm{AA}$.

\section{Precision of Predicted $C P$ and $A A$ Bioavailability Estimates of Hypothetical Diets}

To gain insight in the precision of the bioavailability estimates based on the regression Eq. [2] and [4], 0.95 confidence limits for the predicted value using a simulation procedure were derived. Standard formulas cannot be used here because the predicted value for $\operatorname{sID}_{\mathrm{AA}}$ is based on 2 consecutive regression formulas and a calculation of $\operatorname{sID}_{\mathrm{N}}$ in between. For each of the 10 standard diets and each of $11 \mathrm{AA}$, the full prediction process was simulated 5,000 times, including obtaining the necessary data sets for $\mathrm{sIO}_{\mathrm{N}}$ and $\mathrm{sID}_{\mathrm{AA}}$. The whole procedure consists of 3 steps, with, in total, 8 substeps. The first step is to simulate new data assuming we know the true models for Eq. [2] and [4], estimate the model parameters, and calculate a prediction. The second step is to simulate a "real" value for $\mathrm{sID}_{\mathrm{AA}}$, assuming the same true models. Step 3 is to calculate the difference between the 2 values, which is the (simulated) prediction error. Then, based on 5,000 values, calculate the $95 \%$ range of prediction errors for individual dogs. Note, in the description of the steps below, that, for each diet, $\mathrm{aFO}_{\mathrm{N}}$ and $\mathrm{IN}_{\mathrm{N}}$ are known.

Step 1.1: Obtain data on which estimates of $A_{N}$ and $\mathrm{B}_{\mathrm{N}}$ in Eq. [2] can be can based. These data are "obtained" by simulating a data set for $\mathrm{sIO}_{\mathrm{N}}$ of the same size $(n=158)$, using the same $\mathrm{aFO}_{\mathrm{N}}$ values as in the real data set and assuming Eq. [2] as the true model with $\mathrm{A}_{\mathrm{N}}=$ -0.0345 and $\mathrm{B}_{\mathrm{N}}=1.3967$ and $\sigma_{1}=0.08632$, the $\mathrm{SD}$ of $\varepsilon_{1}$.

Step 1.2: From this data set, derive the estimates $\widehat{A}_{N}, \widehat{B}_{N}$, and $\hat{o}_{1}$ and predict $\mathrm{sIO}_{\mathrm{N}}$ (minimum $0.01)$, given $\mathrm{aFO}_{\mathrm{N}}$ for the specific diet.
Table 1. Coefficients of the linear relationships ${ }^{1}$ between standardized ileal digestibility of individual essential and the sum of nonessential AA ( $\sum$ NEAA) and the standardized ileal digestibility of $\mathrm{N}\left(\mathrm{sID}_{\mathrm{N}} ; \%\right)$ in adult dogs

\begin{tabular}{lrccc}
\hline \hline AA & $\mathrm{A}_{\mathrm{AA}}$ & $\mathrm{B}_{\mathrm{AA}}$ & $R^{2}$ & $\sigma_{\mathrm{AA}}$ \\
\hline Arg & 35.86 & 0.658 & 0.912 & 1.846 \\
Cys & -84.73 & 1.800 & 0.934 & 4.425 \\
His & -14.35 & 1.140 & 0.664 & 7.335 \\
Ile & 11.82 & 0.882 & 0.925 & 2.275 \\
Leu & 13.29 & 0.868 & 0.919 & 2.329 \\
Lys & 5.10 & 0.964 & 0.883 & 3.177 \\
Met & 49.35 & 0.459 & 0.612 & 3.303 \\
Phe & 21.24 & 0.758 & 0.837 & 3.021 \\
Thr & -8.89 & 1.090 & 0.817 & 4.669 \\
Tyr & 12.42 & 0.849 & 0.679 & 5.271 \\
Val & 6.09 & 0.918 & 0.797 & 4.191 \\
NEAA $^{2}$ & 2.04 & 0.967 & 0.953 & 1.977 \\
\hline
\end{tabular}

${ }^{1}$ The standardized ileal digestibility of $\mathrm{AA}=$ the intercept in percent $\left(\mathrm{A}_{\mathrm{AA}}\right)$ + the slope of the regression line $\left(\mathrm{B}_{\mathrm{AA}}\right) \times \mathrm{sID}_{\mathrm{N}} \cdot \sigma \mathrm{AA}=\mathrm{SD}$ of error term.

${ }^{2} \mathrm{Ala}+\mathrm{Asp}+\mathrm{Glu}+\mathrm{Gly}+$ Pro + Ser.

Step 1.3: Calculate $\operatorname{sID}_{\mathrm{N}}$, using Eq. [3].

Step 1.4: Obtain data on which estimates of $\mathrm{A}_{\mathrm{AA}}$ and $\mathrm{B}_{\mathrm{AA}}$ in Eq. [4] can be based. These data are "obtained" by simulating a data set of 24 observations on $\mathrm{SID}_{\mathrm{AA}}$ based on Eq. [4] with $\mathrm{A}_{\mathrm{AA}}$, $\mathrm{B}_{\mathrm{AA}}$, and the $\mathrm{SD}$ of $\varepsilon_{2}, \sigma_{\mathrm{AA}}$, given in Table 1 for each $\mathrm{AA}$. The first 24 simulated $\mathrm{sID}_{\mathrm{N}}$ values of step 1.3 are used as $\mathrm{SID}_{\mathrm{N}}$ values.

Step 1.5: From this data set, derive $\widehat{A_{A A}}, \widehat{B_{A A}}$ and $\hat{o}_{2}$ and use these to predict SID $_{\mathrm{AA}}$.

Step 2.1: Using the assumed true model of step 1.1, simulate the "true" value of $\mathrm{sIO}_{\mathrm{N}}$ (minimum value 0.01 ) with for $\varepsilon_{1}$, a value from a normal distribution with mean of zero and $\mathrm{SD} \sigma_{1}$.

Step 2.2: Calculate the corresponding value of $\operatorname{sID}_{\mathrm{N}}$ (maximum value 99) using Eq. [3].

Step 2.3: Calculate a simulated "true" value for sID $_{\mathrm{AA}}$ using Eq. [4] and $\mathrm{A}_{\mathrm{AA}}$ and $\mathrm{B}_{\mathrm{AA}}$ as in Table 1 with, for $\varepsilon_{2}$, a value from a normal distribution with mean of zero and $\mathrm{SD} \sigma_{2}=\sigma_{\mathrm{AA}}$, as shown in Table 1.

Step 3: Derive the prediction error as the difference between simulated true value (step 2.3) and prediction (step 1.5) for $\mathrm{sID}_{\mathrm{AA}}$.

From the 5,000 simulated values, the error margin for the prediction as half of the difference between the 0.975 percentile (125th but highest value) and 0.025 percentile (the 125th but lowest value) was derived and these were used to calculate the $95 \%$ limits for the confidence intervals for individual prediction. This method assumes symmetry in the prediction errors, so we tested for normality of these errors using 110 quantile-quantile plots (10 diets for each of $11 \mathrm{AA}$ ). 


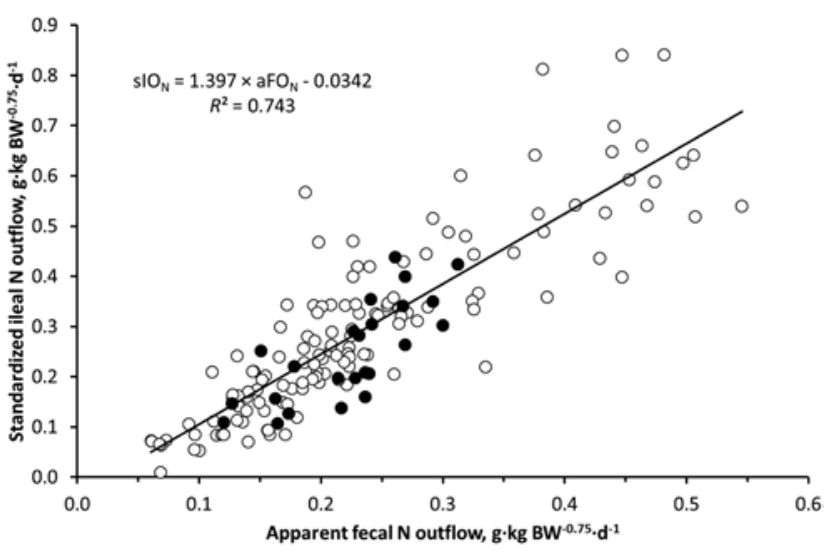

Figure 1. Relation between apparent fecal outflow of $\mathrm{N}\left(\mathrm{aFO}_{\mathrm{N}}\right)$ and standardized ileal outflow of $\mathrm{N}\left(\mathrm{sIO}_{\mathrm{N}}\right)$ in adult dogs. Data points indicated with open circles ( $0 ; n=134$ diets) are derived from 30 studies reporting apparent ileal and fecal $\mathrm{N}$ digestibility values whereas data points with solid markers $(\bullet ; n=24$ diets $)$ are derived from 6 studies also reporting ileal AA digestibility values.

\section{RESULTS}

The $\mathrm{aFO}_{\mathrm{N}}$ data for 158 canine diets ranged from 0.06 to $0.55 \mathrm{~g} /\left(\mathrm{kg} \mathrm{BW} \mathrm{W}^{0.75} \cdot \mathrm{d}\right)$ and the range for $\mathrm{sIO}_{\mathrm{N}}$ was from 0.01 to $0.84 \mathrm{~g} /\left(\mathrm{kg} \mathrm{BW}^{0.75} \cdot \mathrm{d}\right)$. The significant $(P<0.001)$ linear relation between the $\mathrm{aFO}_{\mathrm{N}}$ and $\mathrm{sIO}_{\mathrm{N}}$ in adult dogs is shown in Fig. 1. The ranges of the 24 diets for which the apparent ileal digestibility of AA were also reported ranged from 0.12 to 0.31 and from 0.11 to $0.44 \mathrm{~g} /\left(\mathrm{kg} \mathrm{BW}^{0.75} \cdot \mathrm{d}\right)$, respectively. The $\mathrm{aFO}_{\mathrm{N}}$ was generally lower than the corresponding $\mathrm{sIO}_{\mathrm{N}}$ and the differences between $\mathrm{aFO}_{\mathrm{N}}$ and $\mathrm{sIO}_{\mathrm{N}}$ as well as the variability increased with increasing $\mathrm{aFO}_{\mathrm{N}}$ (slope regression line 1.397; $P<0.001)$. The intercept was significant at $P<$ 0.05 with the residual $\mathrm{SD}$ for $\mathrm{sIO}_{\mathrm{N}}$ being 0.0863 .

The $\mathrm{sID}_{\mathrm{N}}$ values of the 24 diets to correlate $\mathrm{sID}_{\mathrm{N}}$ to $\operatorname{sID}_{\Sigma \text { AAN }}$ ranged from 61 to $90 \%$ (Fig. 2). The $\mathrm{sID}_{\mathrm{N}}$ was highly correlated with $\operatorname{sID}_{\Sigma \mathrm{AAN}}\left(R^{2}=0.958\right)$ and the regression line $(P<0.001)$ showed a strong concordance between both parameters $\left(\mathrm{sID}_{\mathrm{N}}=-1.580+1.006 \times\right.$ $\left.\mathrm{SID}_{\Sigma \mathrm{AAN}}\right)$. The linear regression parameters $\left(\mathrm{A}_{\mathrm{AA}}\right.$ and $\mathrm{B}_{\mathrm{AA}}$ ) and the $R^{2}$ of the regression equations for each essential AA (EAA) and the sum of nonessential AA (NEAA) are presented in Table 1. A strong relationship $\left(R^{2}>0.90\right)$ was obtained for Arg, Cys, Ile, Leu, and the sum of NEAA ( NEAA), with Met, His, and Tyr having coefficients of determination between 0.60 and 0.70 .

The simulated sID of N, EAA, and NEAA for the 10 diets varying in $\mathrm{CP}$ content and $\mathrm{aFD}_{\mathrm{N}}$ are presented in Table 2. Standardized ileal N digestibility values were 4.7 to 10.3 percentage units lower than the set $\mathrm{aFD}_{\mathrm{N}}$ values used (80 or $70 \%$ ) for the simulation. Arginine and Met had a higher sID than for the fecal set point (i.e., 80 and 70\%), whereas other AA had lower values, with Cys having a sID of $22.7 \%$ for the diet with a $70 \% \mathrm{aFD}_{\mathrm{N}}$ and $42 \% \mathrm{CP}$. Increasing dietary $\mathrm{CP}$

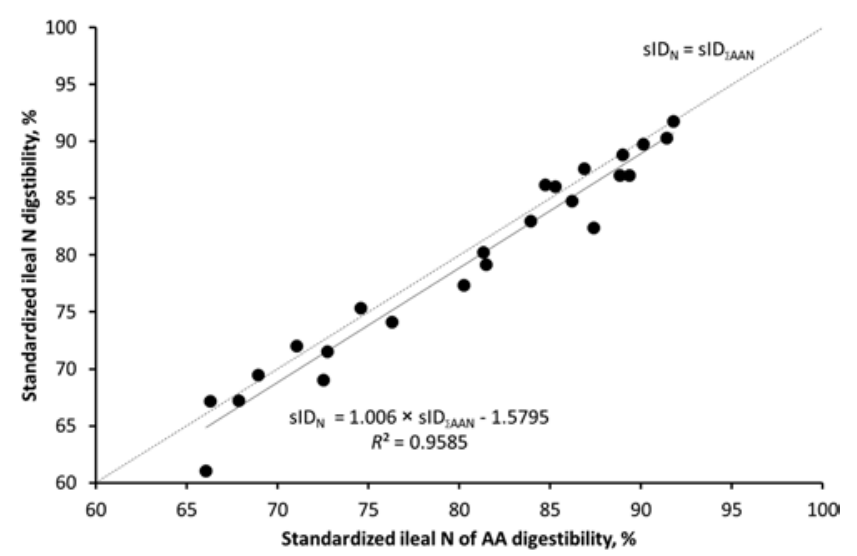

Figure 2. Relationship between standardized ileal digestibility of $\mathrm{N}\left(\operatorname{sID}_{\mathrm{N}}\right)$ and the standardized ileal digestibility of the sum of $\mathrm{N}$ of AA $\left(\operatorname{sID}_{\Sigma \mathrm{AAN}}\right)$ in adult dogs $(n=24$ diets $)$.

content resulted in minimal change of the estimates of $\mathrm{sID}_{\mathrm{AA}}$ but decreased the range of the $95 \%$ confidence interval. Cysteine and His had the largest 95\% confidence intervals of all AA. Finally, it appeared that the prediction error values were very close to being normally distributed. The 110 normality tests, each using 1,000 prediction errors, showed significant deviation from normality in only 10 cases. Even in these cases, the quantile-quantile plot showed near normality.

\section{DISCUSSION}

The present study derived bioavailability estimates for $\mathrm{CP}$ and $\mathrm{AA}$ to convert minimum, physiological requirements to practical allowance estimates of these nutrients in maintenance dog foods. Bioavailability estimates are used in nutrient requirement tables for dogs and cats to derive nutrient requirement estimates for foods manufactured using various heat treatments, less digestible ingredients, and extended periods of storage, that is, commercial diets. As the physiological minimum $\mathrm{CP}$ and AA requirement estimates of the NRC (1995, 2006) have been determined using unprocessed diets formulated from highly digestible ingredients and expressed in (units of) bioavailable nutrients, these values can be considered to represent the minimum physiological requirements. A correction factor, therefore, needs to account for the difference in bioavailability of nutrients between the highly digestible diets used to determine the physiological minimal requirements and the relatively lower digestibility of nutrients in commercial diets.

All studies from which the minimum AA requirement estimates for adult dogs have been derived (NRC, 1995, 2006) have used AA mixtures. The use of an AA mixture or protein-free diet to determine endogenous ileal AA losses results in lower values compared with diets containing peptides or protein (Butts et al., 1992; Hendriks et al., 2002). Additional endogenous losses 
Table 2. Simulated standardized ileal digestibility (sID; \%) of $\mathrm{N}$ and essential and nonessential AA for 10 diets varying in $\mathrm{CP}$ content $(\mathrm{g} / \mathrm{kg})$ and apparent fecal digestibility of $\mathrm{N}\left(\mathrm{aFD}_{\mathrm{N}} ; \%\right)$ fed to an adult $\operatorname{dog}^{1}$ of $20 \mathrm{~kg} \mathrm{BW}$. Values are estimate \pm error margin for $95 \%$ prediction interval

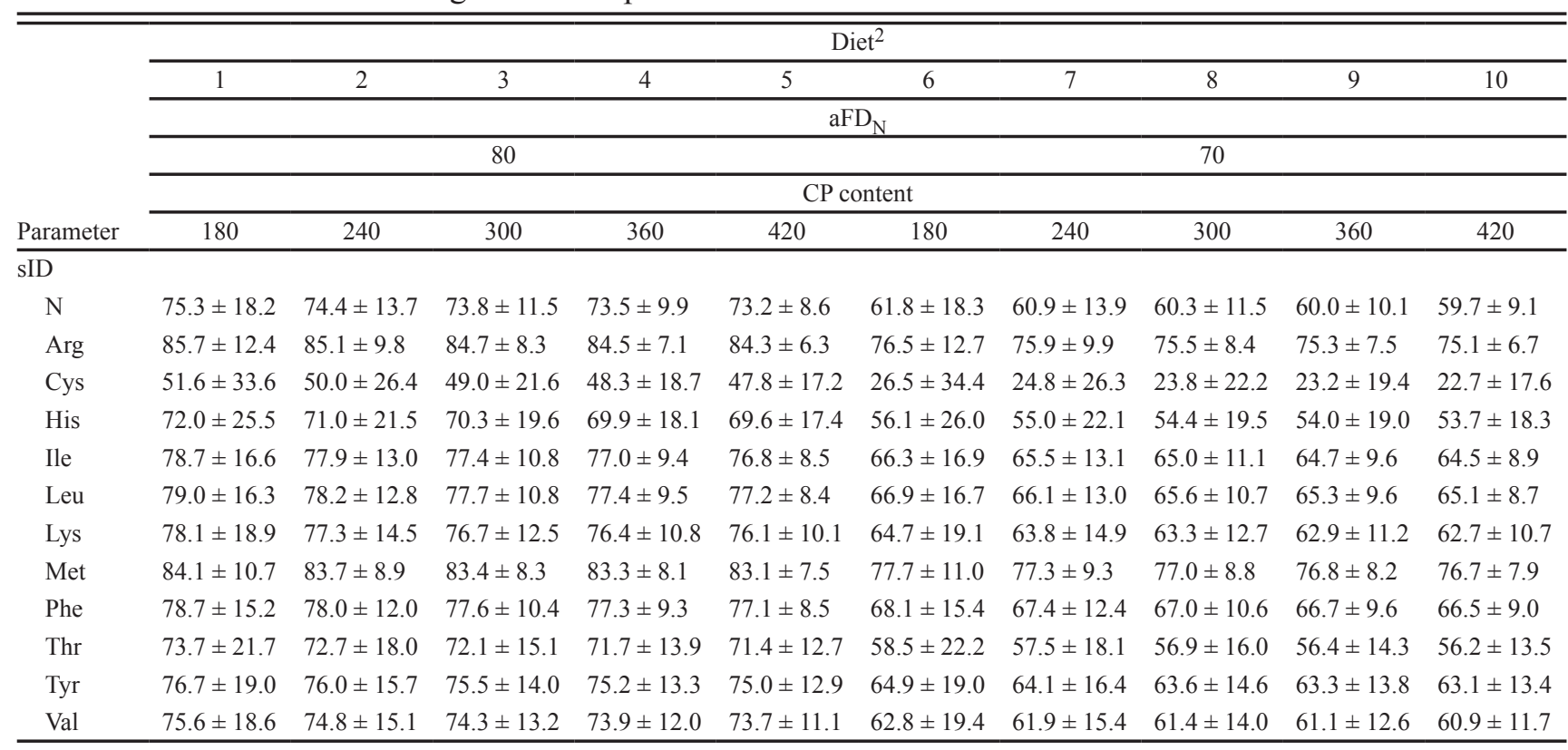

${ }^{1}$ Daily energy requirements estimated as $544 \mathrm{~kJ} \mathrm{ME} / \mathrm{kg} \mathrm{BW}^{0.75}$ (130 kcal ME/kg BW ${ }^{0.75}$; NRC, 2006).

${ }^{2}$ Diets are assumed to contain $16.75 \mathrm{MJ} \mathrm{ME} / \mathrm{kg}(4,000 \mathrm{kcal} \mathrm{ME} / \mathrm{kg})$.

not related to DMI, for example, protein, fiber, and nutritionally active factors, are, therefore, not part of the minimum requirement estimates of the NRC (1995, 2006) and should, as such, be taken into account as an integral component of a bioavailability factor. As such, $\mathrm{aFO}_{\mathrm{N}}$ was related to $\mathrm{SIO}_{\mathrm{N}}$ and not to true ileal outflow of $\mathrm{N}$ or $\mathrm{aIO}_{\mathrm{N}}$. The additional endogenous ileal losses due to various dietary factors as well as endogenous large intestinal losses in the approach used here are now represented in the relationship between $\mathrm{aFO}_{\mathrm{N}}$ and $\mathrm{sIO}_{\mathrm{N}}$. As the latter relationship is based on 158 values derived from diets varying in composition, ingredients used, type, and processing, specific endogenous losses generated by commercial diets are represented in this relationship and contained within the variation observed.

Bioavailability of dietary AA should be measured at the terminal ileum as AA absorption occurs almost exclusively in the small intestine of dogs, with the large intestine making an insignificant contribution to overall AA supply. In the large intestine, however, significant metabolism of dietary and endogenous AA occur, making measurement of total tract $\mathrm{CP}$ and $\mathrm{AA}$ digestibility incorrect as an estimate of absorption (Hendriks et al., 2012). The large intestine of dogs is, compared with that of pigs and rats, relatively "underdeveloped" (Snipes and Kriete, 1991; Snipes, 1997) and one can argue that metabolism of $\mathrm{N}$ would be minimal. The latter, however, is not the case, and experimental evidence shows significant microbial catabolism of undi- gested and endogenous $\mathrm{N}$ components, utilization of $\mathrm{N}$ components for microbial growth, and absorption of $\mathrm{NH}_{3}$ from catabolized AA in the large intestine of dogs (Hendriks et al., 2012). The relationship between $\mathrm{aFO}_{\mathrm{N}}$ and $\mathrm{sIO}_{\mathrm{N}}$ indicates that the net result of these processes is generally a disappearance of $\mathrm{N}$ in the large intestine and, hence, that the apparent fecal digestibility method significantly overestimates the digestibility at the terminal ileum especially when $\mathrm{IN}_{\mathrm{N}}$ is high (Fig. 1).

Based on the 24 diets for which ileal AA and $\mathrm{N}$ digestibility data were available, the $\mathrm{sID}_{\mathrm{N}}$ was shown to be nearly perfectly correlated to $\mathrm{SID}_{\Sigma \mathrm{AAN}}$, indicating that at the terminal ileum, the digestibility of $\mathrm{N}$ is a highly accurate estimate of the digestibility of the sum of $\mathrm{N}$ of AA. The digestibility of individual AA, however, can vary markedly. Some AA showed a strong $\left(R^{2}>0.90\right)$ linear relationship with $\mathrm{sID}_{\mathrm{N}}$, such as Arg, Cys, Ile, Leu, and $\Sigma$ NEAA (Table 2). The latter relationships are based on a limited data set consisting of 24 diets ranging from commercial dry foods to experimental diets containing 2 or more protein sources. In order to derive accurate bioavailability estimates, the relationship between $\operatorname{sID}_{\mathrm{N}}$ and SID of individual AA should preferably be based on a larger data set of representative commercial canine foods of various types. Such a database, however, is not available and unlikely to become available in the future unless new, minimally invasive methodologies are developed that allow accurate measurement of AA and $\mathrm{N}$ digestibility at the terminal ileum of dogs. As 
such, the approach taken here was to use studies reporting SID of individual AA where the protein originated from 2 or more sources as the protein in the majority of commercial pet foods originates from various ingredients. This approach can be critiqued just as the approach to include data from studies where pure starch and fat sources were used in combination with 1 protein source. The latter data can be considered to be not representative of commercial diets. Studies used to derive the relationship included data from Hendriks and Sritharan (2002) and who reported the digestibility of 6 commercial canine dry foods, and Tjernsbekk et al. (2014), who also used, besides a protein source (lamb, poultry, or fish meal), wheat and corn. Bednar et al. (2000) used various ingredients that contained protein including wheat, corn, wheat gluten meal, beef and bone meal, poultry byproduct meal, or poultry meal. Diets used by Clapper et al. (2001) contained chicken bone residue next to a protein source and Gajda et al. (2005) used various protein sources. Although 5 other studies were found to report apparent ileal $\mathrm{CP}$ and AA digestibility values in adult dogs, their data were not used in the present study. Zuo et al. (1996) did not report the DM content of the diets and Hill et al. (2001), Yamka et al. (2003, 2005), and Johnson et al. (1998) investigated the digestibility of diets containing only a single protein source.

A simulation model was developed, using the various relationships derived, to estimate SID of N, EAA, and NEAA for 10 diets varying in CP content and apparent $\mathrm{aFD}_{\mathrm{N}}$ for an adult dog of $20 \mathrm{~kg}$ BW. Mean values and the $95 \%$ confidence intervals are provided in Table 2. The $\mathrm{aFD}_{\mathrm{N}}$ of $80 \%$ was used as this is the lower level considered to be normal for canine maintenance diets by the European Pet Food Industry Federation (2012) and to allow direct comparison with values from the NRC (2006). The use of $80 \%$ as an average $\mathrm{aFD}_{\mathrm{N}}$ for commercial pet foods is supported by Hervera (2011) and Hendriks et al. (2013), who reported mean values for commercial dry foods close to $80 \%$ ( 82.4 and $81.9 \%$, respectively). Kendall et al. (1982) reported mean values $(n=106)$ of 83,84 , and $77 \%$ for wet, intermediate, and dry commercial canine foods. Hall et al. (2013) reported standardized total tract protein digestibility coefficients for 331 dry and moist canine foods of 89.7 and $88.0 \%$, respectively. Expression to apparent digestibility values yields estimates that are approximately 6 percentage units lower. Although the apparent digestibility values reported by Hall et al. (2013) are approximately $83 \%$, two-thirds of the foods were not commercially available and premium foods were overrepresented (D. E. Jewell, Hill's Pet Nutrition, Topeka, Kansas, personal communication). Although a value of $70 \%$ appears to be low, Hervera (2011) reported an $\mathrm{aFD}_{\mathrm{N}}$ value in commercial dog foods of $71 \%$. Table 2 shows that $\operatorname{sID}_{\mathrm{N}}$ values decrease as the
$\mathrm{CP}$ content of a diet increases. The latter is explained by the increased large intestinal $\mathrm{N}$ fermentation as seen in diets with a higher $\mathrm{aFD}_{\mathrm{N}}$. Yamka et al. (2003) showed an increased large intestinal digestibility with increasing $\mathrm{IN}_{\mathrm{N}}$ in dogs fed low-ash poultry meal as a protein source. As increased large intestinal fermentation occurs with increasing $\mathrm{IN}_{\mathrm{N}}, \mathrm{sID}_{\mathrm{N}}$ is lower at the same $\mathrm{aFD}_{\mathrm{N}}$. The sID of Cys ( $\left.\mathbf{s I D}_{\mathbf{C y s}}\right)$ was lowest of all AA with values as low as $22.7 \%$ obtained for diets containing $42 \% \mathrm{CP}$ and a $70 \% \mathrm{aFD}_{\mathrm{N}}$. The latter is largely due to the observed relationship between $\operatorname{sID}_{\mathrm{N}}$ and $\operatorname{sID}_{\mathrm{Cys}}$, which had the highest slope (1.800) of all AA. The data in Table 2 indicates that diets with a lower $\mathrm{SID}_{\mathrm{N}}$ contain relatively more Cys, His, and Thr. There was no apparent relationship between intake of Cys and $\mathrm{sID}_{\mathrm{Cys}}$, indicating that the lower digestibility of Cys is not caused by endogenous Cys losses.

The bioavailability estimates for $\mathrm{CP}$ and AA used by the NRC (2006), the Association of American Feed Control Officials (2011), and the European Pet Food Industry Federation (2012) and the diets with an assumed $\mathrm{aFD}_{\mathrm{N}}$ of 80 and $70 \%$ are presented in Table 3 . The NRC (2006) uses a standard correction factor of $1.25(1 / 0.8)$ for $\mathrm{CP}$ and $\mathrm{AA}$ based on the observation that good quality commercial canine diets can be expected to have an apparent fecal $\mathrm{N}$ digestibility in excess of $80 \%$. Hervera (2011), however, reported $\mathrm{aFD}_{\mathrm{N}}$ values of commercial canine diets as low as $71 \%$. In addition to the inaccuracy of the apparent fecal digestibility assay, the fecal digestibility of individual AA is not equal to that of $\mathrm{N}$ for the majority of the AA. As such, when the lower confidence limit of the SID estimates for the various diets in the present study are compared, it is clear that, overall, the values of the NRC (2006) are erroneous. The Association of American Feed Control Officials (2011) and the European Pet Food Industry Federation (2012) use different estimates depending on the AA without citing scientific studies consulted or clear argumentation to derive different estimates. The larger estimate of the European Pet Food Industry Federation and the Association of American Feed Control Officials for CP seems to be close to the value observed in the present study for the low digestible diets (70\%). The Association of American Feed Control Officials estimates for Arg and Lys are higher and the estimates for His, Ile, Leu, Thr, and Val are lower than diets 1 through 10. For the European Pet Food Industry Federation, only the estimate for Arg is higher; the others are either similar to the lowest estimate (Diet 1) or lower than the estimates calculated here. Inaccurate bioavailability estimates may lead to recommended nutrient concentrations that, when used in the formulation of commercial diets, will not ensure that minimum physiological requirements are met.

Two main factors can contribute to differences between bioavailability and SID of CP and AA, namely 
Table 3. Minimal CP and AA requirements for adult dogs, currently used bioavailability estimates for nutrient guidelines, and range of calculated estimates based in standardized ileal digestibility (sID) values at the lower $95 \%$ confidence interval for diets (16.75 MJ ME/ $\mathrm{kg}$ ) ranging in CP content (180 to $420 \mathrm{~g} / \mathrm{kg}$ ) and apparent fecal $\mathrm{N}$ digestibility of 80 (diets 1 to 5 ) or $70 \%$ (diets 6 to 10 )

\begin{tabular}{|c|c|c|c|c|c|c|}
\hline \multirow[b]{2}{*}{$\underline{\text { Parameter }}$} & \multirow[b]{2}{*}{$\mathrm{MR}^{1}$} & \multicolumn{3}{|c|}{ Estimates } & \multicolumn{2}{|c|}{$1 / \mathrm{sID}$} \\
\hline & & $\begin{array}{l}\text { NRC, } \\
2006\end{array}$ & $\begin{array}{l}\text { Association of American Feed } \\
\text { Control Officials, } 2011\end{array}$ & $\begin{array}{l}\text { European Pet Food Industry } \\
\text { Federation, } 2012 \\
\end{array}$ & $\begin{array}{l}\text { Diets } 1 \text { to } 5 \\
(80 \%)\end{array}$ & $\begin{array}{c}\text { Diets } 6 \text { to } 10 \\
(70 \%)\end{array}$ \\
\hline$\overline{\mathrm{CP}}$ & 80 & 1.25 & 2.25 & 2.25 & $1.55-1.75$ & $1.98-2.30$ \\
\hline Arg & 2.8 & 1.25 & 1.82 & 1.86 & $1.28-1.36$ & $1.46-1.57$ \\
\hline His & 1.5 & 1.27 & 1.20 & 1.53 & $1.92-2.15$ & $2.82-3.32$ \\
\hline Ile & 3.0 & 1.27 & 1.23 & 1.53 & $1.46-1.61$ & $1.80-2.02$ \\
\hline Leu & 5.4 & 1.26 & 1.09 & 1.52 & $1.45-1.59$ & $1.77-1.99$ \\
\hline Lys & 2.8 & 1.25 & 2.25 & 1.50 & $1.52-1.69$ & $1.92-2.19$ \\
\hline Met & 2.6 & 1.27 & - & 1.19 & $1.32-1.36$ & $1.45-1.50$ \\
\hline Phe & 3.6 & 1.25 & - & 1.50 & $1.46-1.57$ & $1.74-1.90$ \\
\hline Thr & 3.4 & 1.27 & 1.45 & 1.55 & $1.70-1.92$ & $2.34-2.75$ \\
\hline Trp & 1.1 & 1.26 & 1.41 & 1.53 & - & - \\
\hline Val & 3.9 & 1.26 & 1.00 & 1.51 & $1.60-1.75$ & $2.03-2.30$ \\
\hline
\end{tabular}

${ }^{1} \mathrm{MR}=$ minimal requirement (in grams for a diet containing 16.75 MJ ME/kg [4,000 kcal ME/kg; NRC, 2006]).

the chemical form in which the AA is absorbed compared with which it is measured and fermentation in the upper digestive tract (Stein et al., 2007). Assuming fermentation of dietary AA in the upper digestive tract of dogs is minimal, ileal digestibility equals bioavailable for the majority of AA. The exceptions are AA that are absorbed in a chemical form that are utilized to a different extent by metabolism compared with measurement by the ileal digestibility assay. The classic example is Lys, the most reactive AA to form early, and advanced Maillard reaction products, which, under the hydrolysis conditions with strong acid, reverts back to Lys. Estimates of the sID of Lys ( sID $_{\text {Lys }}$ ) in diets with significant amounts of Lys involved in the Maillard reaction, therefore, are inaccurate to provide bioavailability estimates for Lys. Determination of $\operatorname{SID}_{\text {Lys }}$ with a free $\varepsilon$-amino group (i.e., reactive Lys) circumvents this inaccuracy and provides a more reliable bioavailability estimate (Stein et al., 2007). In commercial dog foods, several studies as reviewed by Van Rooijen et al. (2013) have shown a large difference between reactive and total Lys content. In commercial cat foods, the standardized ileal reactive Lys content is significantly lower compared with standardized ileal total Lys content (Rutherfurd et al., 2007). Therefore, the bioavailability estimates calculated for total Lys in the present study $\left(1.52-1.69\right.$ for the $\left.80 \% \mathrm{aFD}_{\mathrm{N}}\right)$ are likely too low.

In addition to Lys, other AA may be absorbed in a form that is not fully utilized by metabolism, such as Met and Cys. The sID assay does not account for the various oxidation states of dietary Met and Cys as during chemical analysis, these AA are completely oxidized to methionine sulfone and cysteic acid, respectively. Dietary methionine sulfone and cysteic acid are completely nutri- tionally unavailable in rats, chickens, and turkeys whereas cysteic acid can be used for taurine synthesis in several species including cats (Rutherfurd and Moughan, 2008). The various oxidation states of Met and Cys in dog foods are largely unknown as well as the utilization of oxidized Met and Cys by the dog's metabolism.

\section{Conclusions}

The present study derived bioavailability estimates for $\mathrm{CP}$ and $\mathrm{AA}$ to convert minimum physiological requirements to practical allowance estimates for maintenance dog foods using literature data. The generated bioavailability estimates show that estimates currently used by the NRC (2006) are too small. In general, the estimates used by the European Pet Food Industry Federation (2012) and the Association of American Feed Control Officials (2011) are too small as well, with the exception of N, Arg, and Lys. Additional research on the chemical form of specific AA (e.g., Lys, Met, and Cys) present in diets for dogs is required to provide more robust estimates.

\section{LITERATURE CITED}

Association of American Feed Control Officials (AAFCO). 2011. 2011 official publication. AAFCO, Atlanta, GA.

Batterham, E. S. 1992. Availability and utilization of amino acids for growing pigs. Nutr. Res. Rev. 5:1-18. doi:10.1079/ NRR19920004.

Bednar, G. E., S. M. Murray, A. R. Patil, E. A. Flickinger, N. R. Merchen, and G. C. Fahey Jr. 2000. Selected animal and plant protein sources affect nutrient digestibility and fecal characteristics of ileally cannulated dogs. Arch. Anim. Nutr. 53:127-140. 
Butts, C. A., P. J. Moughan, and W. C. Smith. 1992. Protein nitrogen, peptide nitrogen and free amino acid nitrogen in endogenous digesta nitrogen at the terminal ileum of the rat. J. Sci. Food Agric. 59:291-298. doi:10.1002/jsfa.2740590304.

Clapper, G. M., C. M. Grieshop, N. R. Merchen, J. C. Russett, J. L. Brent Jr., and G. C. Fahey Jr. 2001. Ileal and total tract nutrient digestibilities and fecal characteristics of dogs as affected by soybean protein inclusion in dry, extruded diets. J. Anim. Sci. 79:1523-1532.

European Pet Food Industry Federation (FEDIAF). 2012. Nutritional guidelines for complete and complementary pet food for cats and dogs. FEDIAF, Brussels, Belgium.

Gajda, M., A. E. Flickinger, C. M. Grieshop, L. L. Bauer, N. R. Merchen, and G. C. Fahey Jr. 2005. Corn hybrid affects in vitro and in vivo measures of nutrient digestibility in dogs. J. Anim. Sci. 83:160-171.

Hall, J. A., L. D. Melendez, and D. E. Jewell. 2013. Using gross energy improves metabolizable energy predictive equations for pet foods whereas undigested protein and fiber content predict stool quality. PLoS ONE 8:e54405.

Hendriks, W. H., C. M. Grieshop, D. V. Thomas, G. Bosch, and G. C. Fahey Jr. 2013. Comparison of ileal and fecal nutrient digestibility of dry canine foods. J. Anim. Sci. 91:3807-3814. doi:10.2527/jas.2012-5864.

Hendriks, W. H., and K. Sritharan. 2002. Apparent ileal and fecal digestibility of dietary protein is different in dogs. J. Nutr. 132:1692S-1694S.

Hendriks, W.H., K. Sritharan, and S. M. Hodgkinson. 2002. Comparison of the endogenous ileal and faecal amino acid excretion in the dog (Canis familiaris) and the rat (Rattus rattus) determined under protein-free feeding and peptide alimentation. J. Anim. Physiol. Anim. Nutr. 86:333-341. doi:10.1046/j.1439-0396.2002.00391.x.

Hendriks, W. H., J. van Baal, and G. Bosch. 2012. Ileal and faecal protein digestibility measurement in monogastric animals and humans: A comparative species view. Br. J. Nutr. 108:S247-S257. doi:10.1017/S0007114512002395.

Hervera, M. 2011. Methods for predicting the energy value of dog foods. PhD Thesis, Universitat de Autònoma de Barcelona, Barcelona, Spain.

Hill, R. C., C. F. Burrows, G. W. Ellison, and J. E. Bauer. 2001. The effect of texturized vegetable protein from soy on nutrient digestibility compared. J. Anim. Sci. 79:2162-2171.

Johnson, M. L., C. M. Parsons, G. C. Fahey Jr., N. R. Merchen, and C. G. Aldrich. 1998. Effects of species raw material source, ash content, and processing temperature on amino acid digestibility of animal by-product meals by cecectomized roosters and ileally cannulated dogs. J. Anim. Sci. 76:1112-1122.
Kendall, P. T., D. W. Holme, and P. M. Smith. 1982. Methods of prediction of the digestible energy content of dog foods from gross energy value, proximate analysis and digestive content. J. Sci. Food Agric. 33:823-831. doi:10.1002/jsfa.2740330903.

Morris, J. G., and Q. R. Rogers. 1994. Assessment of the nutritional adequacy of pet foods through the life cycle. J. Nutr. 124:2520S-2534S.

NRC. 1995. Nutrient requirements of dogs. Natl. Acad. Press, Washington, DC.

NRC. 2006. Nutrient requirements of dogs and cats. Natl. Acad. Press, Washington, DC.

Rutherfurd, S. M., and P. J. Moughan. 2008. Determination of sulfur amino acids in foods as related to bioavailability. J. AOAC Int. 91:907-913.

Rutherfurd, S. M., K. J. Rutherfurd-Markwick, and P. J. Moughan. 2007. Available (ileal digestible reactive) lysine in selected pet foods. J. Agric. Food Chem. 55:3517-3522.

Snipes, R. L. 1997. Intestinal absorptive surface in mammals of different size. Adv. Anat., Embryol. Cell Biol. 138:1-90.

Snipes, R. L., and A. Kriete. 1991. Quantitative investigation of the area and volume in different compartments of the intestine of 18 mammalian species. Z. Saugetierkd. 56:225-244.

Stein, H. H., B. Sève, M. F. Fuller, P. J. Moughan, and C. F. M. de Lange. 2007. Invited review: Amino acid bioavailability and digestibility in pig feed ingredients: Terminology and application. J. Anim. Sci. 85:172-180. doi:10.2527/jas.2005-742.

Tjernsbekk, M. T., A.-H. Tauson, and Ø. Ahlstrøm. 2014. Ileal, colonic and total tract nutrient digestibility in dogs (Canis familiaris) compared with total tract digestibility in mink (Neovison vison). Arch. Anim. Nutr. 68:245-261. doi:10.10 80/1745039X.2014.915137.

Van Rooijen, C., G. Bosch, A. F. B. van der Poel, P. A. Wierenga, L. Alexander, and W. H. Hendriks. 2013. The Maillard reaction and pet food processing: Effects on nutritive value and pet health. Nutr. Res. Rev. 26:130-148. doi:10.1017/S0954422413000103.

Yamka, R. M., U. Jamikorn, A. D. True, and D. L. Harmon. 2003. Evaluation of low-ash poultry meal as a protein source in canine foods. J. Anim. Sci. 81:2279-2284.

Yamka, R. M., S. E. Kitts, and D. L. Harmon. 2005. Evaluation of low-oligosaccharide and low-oligosaccharide low-phyate whole soya beans in canine foods. Anim. Feed Sci. Technol. 120:79-91. doi:10.1016/j.anifeedsci.2005.01.014.

Zentek, J. 1995. Influence of diet composition on the microbial activity in the gastro-instestinal tract of dogs. I. Effects of varying protein intake on the composition of the ileum chyme and faeces. J. Anim. Physiol. Anim. Nutr. 74:43-52. doi:10.1111/j.1439-0396.1995.tb00435.x.

Zuo, Y., G. C. Fahey Jr., N. R. Merchen, and N. L. Bajjalieh. 1996. Digestion responses to low oligosaccharide soybean meal by ileally-cannulated dogs. J. Anim. Sci. 74:2441-2449. 